The measured spin characteristics of the hydrogen atoms in the water vapour, which may indicate the location of ice formation, differ from those of watery comets in our Solar System. This suggests that substantial mixing of ice occurs across a planetary disk, which comets then collect during the early stages of planet formation. Comets are thought to be responsible for delivering water to inner-Solar-System planets such as Earth.

Science 334, 338-340 (2011)

\section{ANIMAL COGNITION}

\section{Tools don't make for brainy birds}

The ability to use tools is not always a sign, or a driver, of intelligence - certainly not in some Galapagos finches.

Various animals use tools such as twigs to gain better access to food sources. This puts them at an evolutionary advantage, so tool use has long been linked to higher cognitive function. But Sabine Tebbich at the University of Vienna and her colleagues found that toolusing woodpecker finches (Cactospiza pallida) are no more adept at a physical task that mimics tool use than nontool-using individuals of the same species. Furthermore, the closely related small tree finch (Camarhynchus parvulus; pictured), which never uses tools, performed just as well at physical tasks as tool-using C. pallida birds,

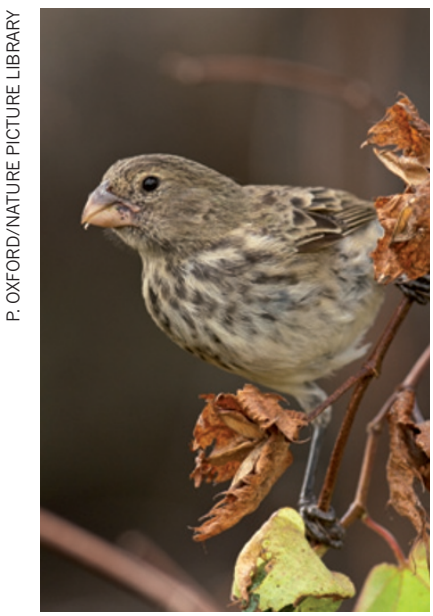

and failed just one of the

learning tasks.

The findings show that physical and cognitive abilities do not always evolve hand-inhand.

Anim. Behav. 82, 945-956

(2011)

CANCER BIOLOGY

\section{A sirtuin helps cells divide}

Some members of the sirtuin protein family have been implicated in age-related diseases. Researchers now report that one family member, SIRT2, regulates cell division and suppresses tumour formation in mice.

SIRT2 localizes to structures that assist in cell division, but its role in the development of cancer has been unclear. Chu-Xia Deng of the National Institutes of Health in Bethesda, Maryland, and his colleagues found that some human tumours produce abnormally low levels of SIRT2, and that mice lacking the Sirt 2 gene are prone to tumours.

Cells lacking SIRT2 also failed to divide properly: about $35 \%$ of Sirt 2 -mutant cells grown in culture had an abnormal number of chromosomes. Lack of SIRT2 reduced the activity of a complex of proteins called APC/C, which is vital for correct apportioning of chromosomes into dividing cells.

Cancer Cell 20, 487-499 (2011)

\section{NEUROSCIENCE}

\section{New neurons} detail memories

Neurons are constantly being born in the adult hippocampus, a region of the brain central to memory formation, but whether they have a role in the making of new memories has been unclear.

Paul Frankland at the Hospital for Sick Children in Toronto, Canada, and his colleagues identified a way

COMMUNITY CHOICE

The most viewed papers in science

\title{
Wipe-on water repellent
}

\section{Highly Read \\ on pubs.acs.org in September}

From non-stick pans to waterproof jackets, water-repellent materials are in high demand. But many of the processes used to deposit hydrophobic coatings are expensive and complicated.

Yong-Lai Zhang at Jilin University in Changchun and Feng-Shou Xiao at Zhejiang University in Hangzhou, both in China, and their colleagues have created a hydrophobic chalk made of nanoporous polydivinylbenzene that can be easily wiped or painted onto surfaces. The porous structure renders the material's surface rough and reduces its contact with water droplets, making the material hydrophobic.

The team tested their coating by applying the fine powder to paper, a piece of silicone and human skin. Fingers smeared in the chalk and dipped in water remained dry. The group speculates that the substance could be used by swimmers to reduce drag or for various industrial applications.

Langmuir 27, 12585-12590 (2011)

to target these new neurons in mice - by genetically manipulating the animals so that an injection of a natural toxin would kill the cells. The authors trained the mice on a memory task, then administered the chemical. The animals' memories faded, but did not disappear completely. For example, a mouse could still remember that a hidden platform was near a patterned visual cue - just not which pattern. The results suggest that adult-generated neurons are essential to the finer details of memory.

J. Neurosci. 31, 15113-15127 (2011)

\section{PHYLOGENETICS}

\section{From Africa to Amazonia}

Fossil teeth from South

America's oldest known rodents reveal that the creatures probably originated in Africa, roughly 40 million years ago.

Because South America has a paucity of fossils older than 34 million years, the

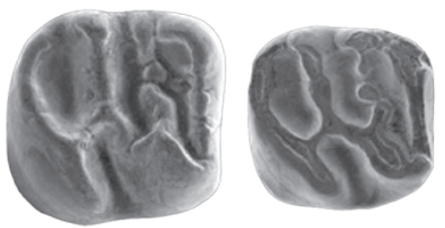

origins of the continent's rodents, including guinea pigs and chinchillas, have been debated. Pierre-Olivier Antoine at the University of Montpellier in France and his colleagues analysed the small, 41-million-year-old fossil teeth (pictured) from the Peruvian Amazon and found strong similarities with the teeth of the rodents' Old World relatives. These animals were probably among the first to adapt to South American habitats and it is likely that their last common ancestor came from Africa, which served as a stopover during the ancestors' dispersal from Asia.

Proc. R. Soc. B http://dx.doi. org/10.1098/rspb.2011.1732 (2011)

\section{DNATURE.COM}

For the latest research published by Nature visit:

www.nature.com/latestresearch 